\title{
AS CONTRIBUIÇÕES DA AFETIVIDADE NA RELAÇÃO PROFESSOR-ALUNO DA EDUCAÇÃO INFANTIL ENUNCIADAS EM ARTIGOS DE PERIÓDICOS (2015-2019)
}

The contributions of affectivity in the teacher-student relation in children's education stated in journal articles (2015-2019)

\section{Maria do Socorro de Araújo Rodrigues ${ }^{\mathrm{I}}$}

RESUMO: Este Trabalho versa sobre a afetividade na relação professor-aluno no processo de ensino e aprendizagem na Educação Infantil enunciados em artigos publicados em periódicos nos últimos cinco anos. Trata-se de uma pesquisa bibliográfica com abordagem qualitativa. Os artigos foram encontrados em buscas no portal de periódicos da CAPES. Eles foram selecionados por meio dos seguintes filtros: palavras-chave: Afetividade and Educação Infantil, no título; data de publicação: nos últimos cinco anos; tipo de material: artigos. As produções foram analisadas à luz da técnica de Análise Textual Discursiva. Os resultados apontam para a importância da afetividade no processo de ensino e aprendizado na etapa da Educação Infantil. Identificamos convergências para o sentido da afetividade quando direcionada à relação professor-aluno; averiguamos que ao abordarem sobre afetividade no processo de ensino, as produções apresentaram ações que podem contribuir com os laços afetivos.

Palavras-chaves: Afetividade. Educação Infantil. Relação professor-aluno.

ABSTRACT: This work deals with affectivity in the teacher-student relationship in the teaching and learning process in Early Childhood Education listed in articles published in journals in the last five years. This is a bibliographical research with a qualitative approach. The articles were found in searches in the CAPES journal portal. They were selected through the following filters: keywords: Affectivity and Early Childhood Education, in the title; date of publication: in the last five years; material type: articles. The productions were analyzed in the light of the Discursive Textual Analysis technique. The results point to the importance of affectivity in the teaching and learning process in the early childhood education stage. We identified convergences towards the sense of affectivity when directed to the teacher-student relationship; we found that when addressing about affectivity in the teaching process, the productions presented actions that can contribute to the bonds that affect.

Keywords: Affectivity. Early Childhood Education. Teacher-student relationship.

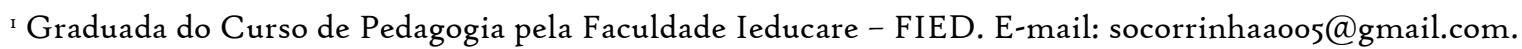




\section{INTRODUÇÃO}

Ao longo da graduação ouvi muitos discursos sobre a importância do professor manter uma relação de afeto e de confiança com seus alunos. Entretanto, a partir do momento que iniciei meu trabalho como auxiliar nas turmas de Educação Infantil na cidade de Tianguá-Ce, foi possível acompanhar mais de perto uma realidade que nos permitiu ter interesse de conhecer de uma forma mais aprofundada a importância e os resultados que o afeto entre professor e aluno poderia proporcionar para o ensino e aprendizado das crianças, principalmente na etapa Educação Infantil.

Compreende-se que o desenvolvimento cognitivo das crianças perpassa por vários aspectos inerentes ao ambiente escolar. Considera-se, principalmente, a afetividade como elemento central no processo de aprendizagem dos estudantes na etapa Educação Infantil.

Conforme a Lei de Diretrizes e Bases da Educação Nacional (LDB 9394/96), indica em seu art. 29, a Educação Infantil é a "primeira etapa da Educação Básica, tendo como finalidade o desenvolvimento integral da criança até seis anos de idade, complementando a ação da família e da comunidade”.

Nesta perspectiva, compreendemos o quanto a Afetividade é de extrema importância para o desenvolvimento cognitivo dos estudantes, pois colaborará para seu desenvolvimento pleno.

Para Wallon (1995 apud Cunha, Amacio, Baccelli, 2020), o contexto social tem grande influência no desenvolvimento da criança, e seu aprendizado e desenvolvimento em cada etapa dependerá do meio na qual está inserida. É a partir das interações que as crianças irão formar suas personalidades e seus aprendizados, desenvolvendo o cognitivo, a imaginação, criatividades, tendo um desenvolvimento integral de acordo com suas necessidades.

Esta pesquisa vem trazendo algumas leis estabelecidas nos documentos do Estatuto da Criança e do Adolescente (ECA), e da Lei de Diretrizes e Bases da Educação Nacional (LDB) e da Base Nacional Comum Curricular (BNCC), que trazem alguns dos direitos das crianças para a aplicação da afetividade no ambiente escolar e também o pensamento de alguns teóricos como Wallon, Silva, França entre outros citados nesta pesquisa, ela ainda terá como embasamento produções encontrados no portal de periódicos da CAPES, os quais contribuíram na análise e discussões desta pesquisa, que procura desenvolver uma melhor compreensão sobre a importância da afetividade na Educação Infantil como forma de ensino e aprendizado.

Diante disto foi levantado o seguinte problema: O que dizem os periódicos sobre afetividade na relação professor e aluno na Educação Infantil?. O objetivo geral deste estudo é identificar como os periódicos apresentam a afetividade na relação professor-aluno no processo de ensino e aprendizagem na Educação 
Infantil no período de 2015 a 2020. Como objetivos específicos buscou-se compreender os sentidos de afetividade apresentados nos periódicos; identificar os discursos sobre afetividade na relação professoraluno na educação infantil; averiguar a importâncias dos laços afetivos nas práticas pedagógicas apresentados nos periódicos.

O estudo compõe uma pesquisa bibliográfica com abordagem qualitativa, e encontra-se organizado da seguinte maneira: Afetividade no processo Ensino e Aprendizado; Educação Infantil nos Documentos Oficiais; Relação Professor-Aluno, Metodologia; Análise e discussões; Concepções de Afetividade na Educação Infantil; Os Sentidos da Afetividade na relação Professor-Aluno; A Importância da Afetividade nas Práticas Pedagógicas para o processo de Ensino e Aprendizado na Educação Infantil e as Considerações Finais.

\section{I.I Afetividade no processo Ensino e Aprendizado}

O processo de ensino e aprendizado realizado através da afetividade vem se fortalecendo cada vez mais no decorrer dos anos, sendo que em alguns séculos atrás, como no século XVII, as crianças não eram vistas com seres que necessitavam de afeto. Eram tratadas como crianças em miniaturas, no decorrer do tempo depois das crianças serem comparadas com anjos, foi compreendido pela sociedade que a criança é um ser frágil que requer cuidados para que possa se desenvolver em todos os aspectos. A partir de então, foram iniciados estudos sobre a importância do afeto com as crianças, principalmente com as menores.

A afetividade é uma ferramenta essencial nas práticas pedagógicas, na qual através dela poderá ser desenvolvido um ensino e aprendizado de uma forma eficaz. Pois o afeto tem o poder de desenvolver o cognitivo, a criatividade e a imaginação da criança, tomando-as pessoas críticas e donas dos seus próprios pensamentos e sentimentos. São os laços afetivos desenvolvidos no ambiente escolar que irão contribuir na formação integral da criança, pois é no ambiente escolar que a criança vai conhecer coisas novas, no qual ela poderá explorar o mundo e aprender a conviver com diferentes pessoas e culturas, pois as crianças não são seres vazios, são seres que trazem consigo emoções e experiências do seu cotidiano familiar. Conforme a BNCC (2017), devido a criança ser, o seu sujeito histórico e de direitos, que interagem, imaginam, brincam, fantasiam, aprendem, desejam, observam, experimentam, narram, questionam e constroem sentidos sobre a natureza e a sociedade produzindo cultura.

As crianças possuem mais facilidade de aprender as coisas ao seu redor, devido ainda estarem passando pelo processo de formação, no qual nesta etapa ela usa muito a imaginação e criatividade e possui mais facilidade de interagir com o meio em que está inserida. Elas são movidas por sentimentos, 
logo, a afetividade neste processo torna-se essencial, pois é através dela que as crianças vão aprender a controlar suas emoções e compreender o que são os sentimentos de raiva, medo, insegurança, aprendendo assim a dominar cada um deles, vindo desta forma a conhecer os principais valores como respeitar o gosto de seus colegas, compreendendo que todos têm uma forma de agir e pensar. Formando assim, a empatia e o respeito pelo o outro, produzindo desta forma cultura. O professor tem a obrigação de estar sempre proporcionando momentos nos quais os alunos possam conhecer-se e conhecer o outro, para que desta forma seja realizado um aprendizado entre todos.

Para Wallon (1981, apud AMORIM, CALIL, 2020 p. 104) a criança se forma na cultura, e a escola é o local responsável pela expansão dessa cultura, independentemente da sua origem social, étnica ou religiosa. Portanto, é no meio em que a criança convive que ela vai adquirir novos conhecimentos que irão contribuir bastante na sua formação. O professor tem uma grande influência na vida das crianças nesta fase, pois ele vai afetar a criança de uma forma negativa ou positiva. O professor deve sempre buscar o bem estar dos discentes, proporcionando bem estar para as crianças, no qual haja respeito e direitos entre todas, independente da classe social, pois elas têm direito de serem bem cuidadas por todos que compõem o ambiente escolar.

A afetividade tem uma função muito importante na formação da criança, sendo que as crianças que recebem afeto no ambiente escolar têm mais possibilidades de se desenvolverem da maneira correta. Este processo torna-se mais importante na etapa da Educação Infantil, devido a criança estar saindo do ambiente familiar para o ambiente escolar. Nesta fase, a criança está passando por adaptações que requerem muito cuidado e atenção do professor, ele deve manter sempre uma relação de afeto com a criança, pois quando não ocorre uma relação entre o professor e o aluno no processo de ensino $e$ aprendizado, o aluno terá mais dificuldades de compreender o assunto abordado, vindo a prejudicar o seu desenvolvimento.

Para Silva (2017) "a história das crianças com dificuldades de aprendizagem se limita a criança com desordem no desenvolvimento da linguagem, da fala, da escrita e das intenções sociais". Isto ocorre quando não é estabelecida a confiança e o diálogo no ambiente escolar, vindo a prejudicar o desenvolvimento da criança afetando sua relação com outras pessoas, e prejudicando assim sua linguagem, deixando a criança com a autoestima baixa. $O$ afeto é de fundamental importância no ambiente escolar, pois ele é a base, o instrumento mais importante para o processo de desenvolvimento da criança. Pois através dele, a criança poderá adquirir um ensino de qualidade de acordo com suas necessidades. Os alunos são movidos por sentimentos, que permeiam todas as fases. A criança requer muito cuidado e atenção, devido ser um ser frágil que ainda está descobrindo o mundo ao seu redor. Pois 
é no período da infância que a criança vai formar sua personalidade e seu aprendizado, podendo analisar e compreender o que é certo ou errado.

A afetividade que é responsável pelos coloridos de nossa vida psíquica e consequentemente pela tonalidade de nossa existência. A vida sem os afetos seria igual para todos, sem a sensibilidade afetiva o mundo perderia todo o colorido e o senso dramático que caracteriza nossas ações e projetos. (GIOVANETTI, 2017, p. 48).

A afetividade afeta o psicológico e o emocional. Quando algo ao redor da criança não vai bem, seu aprendizado não vai ser eficaz, pois os sentimentos envolvem toda a estrutura do indivíduo, quando a criança não é cercada de afeto ela não irá se sentir motivada, não sentirá vontade de explorar o mundo, prejudicado assim seu aprendizado. Portanto, quando a criança se sente segura no ambiente escolar suas habilidades serão desenvolvidas. O professor deve estar sempre buscando estimulá-las, promovendo sempre um bem estar para elas, ele deve procurar conhecer como é a realidade dos seus alunos para que possa ser realizado novos métodos de aprendizado, para que elas possam vir a compreender o assunto abordado, ocorrendo assim um ensino e aprendizado de qualidade na qual irá contribuir na formação da criança.

\section{I.2 Educação Infantil nos Documentos Oficiais}

A etapa da Educação Infantil era vista há muitos anos como apenas um local na qual os pais poderiam deixar seus filhos para poderem ir trabalhar. Mas, ao longo dos anos e com a criação dos documentos como a BNCC, LDB, e o ECA, mudou-se esta realidade. Na qual este local passou a ser um ambiente de aprendizado para as crianças, na qual elas poderiam desenvolver seu raciocínio, seu emocional e seu lado social. Passando assim a ter direitos à etapa da Educação Infantil crianças de o a 5 anos de idade, assim como consta no Art. I 0 O inciso IV do caput do art. 54 da Lei no 8.069, de 13 de julho de 1990 - Estatuto da Criança e do Adolescente, passa a vigorar com a seguinte redação: Art. 54 IV atendimento em creche e pré-escola às crianças de zero a cinco anos de idade. A partir desta lei as crianças passaram a adquirir novos direitos como o direito a educação nos primeiros anos de vida, a partir dos quatro anos de idade o ensino já se torna obrigatório, já com as menores de quatro anos, ainda é opção dos pais colocarem seus filhos nas creches ou não.

Percebe-se que a educação infantil é de fundamental importância na vida das crianças, pois é o local onde elas poderão explorar o mundo, formando sua personalidade e seus pensamentos. É também o local onde muitas crianças que não recebem o afeto da família poderão conhecer um pouco desse sentimento. Por isso, o ambiente escolar deve ser acolhedor, sendo um lugar no qual a criança goste de 
estar. O educador tem grande influência nesta etapa de formação das crianças, se o professor não demostra empatia com elas, suas atitudes poderão vir a prejudicar o emocional, gerando medo e desconfiança, prejudicando assim o desenvolvimento e aprendizagem delas.

[...] afetividade é essencial para o sucesso da aprendizagem no ambiente educacional e social, pois estimula a criança na capacidade de desenvolver as habilidades voltadas para o conhecer, aprender e o conviver em sociedade. São os vínculos que a criança estabelece que produz o seu bem estar pessoal e social $e$, assim a motivação para buscar novas aprendizagens. Neste sentido a ausência da afetividade em um contexto educativo, poderá ocasionar prejuízos incalculáveis no desenvolvimento cognitivo da criança visto que o desenvolvimento da aprendizagem é único, particular e continuo. (SANTOS, 2016, p. 16).

A família é a primeira responsável por estabelecer os vínculos afetivos com a criança, proporcionando segurança e um ambiente saudável no qual ela possa se desenvolver. Mas, essa responsabilidade não é só da família, mas também da escola, pois é de fundamental importância que ao chegar no ambiente escolar a criança encontre todo um afeto no qual ela possa sentir-se segura, protegida e amada, pois é no ambiente escolar que a criança vai aprender a conviver em sociedade e com as diferenças. Ela vai compreender que existem regras a serem cumpridas, aprendendo assim, os principais valores, além de aprenderem a controlar suas próprias emoções. A escola, deve ser um lugar harmonioso e tranquilo e deve ter como principal foco o bem estar da criança.

A afetividade é essencial no ambiente escolar, principalmente na educação infantil, devido a criança estar passando por adaptações, nas quais requerem muito afeto dos professores. De acordo com a Lei de Diretrizes e Bases da Educação Nacional (LDB, 1996), Lei no 9394/96, em seu art. 29, a Educação Infantil, "primeira etapa da educação básica, tem como finalidade o desenvolvimento integral da criança de até 5 (cinco) anos, em seus aspectos físico, psicológico, intelectual e social, complementando a ação da família e da comunidade." É nessa fase que a criança está descobrindo a si mesma e as coisas ao seu redor, por isso, a importância das trocas de afeto são fundamentais nesta etapa.

O professor deve estar sempre estimulando a criança através de práticas pedagógicas, nas quais a criança possa explorar as coisas ao seu redor, pois elas têm mais facilidade de aprender quando estão vivenciando o ato. O professor tem a função de realizar os 5 campos de experiências da BNCC, sempre com afetividade para que a criança possa se desenvolver. De acordo com a BNCC (2017), os campos de experiências são: I eu o outro e o nós; 2 corpo, gestos e movimentos; 3 traços, sons, cores e formas; 4 escuta, fala, pensamentos e imaginação; 5 espaço, tempos e quantidades, relações e transformação nos quais são definidos os objetivos de aprendizagem e desenvolvimentos. É através destes campos de 
experiências desenvolvidos no ambiente escolar, que a criança vai formar sua personalidade e aprendizado podendo compreender o conteúdo abordado a ela.

Estes campos podem ser explorados em brincadeiras, contação de histórias nas atividades de recorte, sempre com a orientação do professor, as atividades desenvolvidas no ambiente escolar devem conter sempre os campos de experiência, essas atividades são muito importantes para o processo de ensino e aprendizado e na construção de vínculos afetivos entre o professor e o aluno. Ainda, conforme a BNCC (2017, p. 23), "na primeira etapa da Educação Básica, e de acordo com os eixos estruturantes da educação infantil (interações e brincadeiras), devem ser assegurados os direitos de aprendizagem e desenvolvimento, para que as crianças tenham condições de aprender e se desenvolver”.

A afetividade tem um papel bastante importante nessa etapa de aprendizagem das crianças da educação infantil, principalmente quando está relacionada ao ensino e aprendizado das crianças. Essa relação fica mais forte na fase de alfabetização, devido às crianças se sentirem mais inseguras, pelo fato de o aluno precisar se esforçar mais nas atividades curriculares.

Portanto, é essencial que o professor conheça as dificuldades de seus alunos para que juntos possam encontrar soluções, esta relação que o educador estabelece com o aluno é de fundamental importância para o processo de aprendizado das crianças e também do professor, pois os dois irão construir conhecimentos juntos, formando os laços afetivos que irão ajudar na formação do indivíduo. Formando assim um ser crítico e pensante, no qual possa ter seus próprios pensamentos, desenvolvendo o cognitivo, a imaginação e a criatividade, podendo assim conviver em uma determinada sociedade.

\subsection{Relação Professor-Aluno}

A Educação Infantil é a porta de entrada da criança para o mundo, pois através dela a criança despertará a curiosidade, a imaginação e os sentimentos. Ela vai aprender a lidar com o novo e com o diferente, despertando sua linguagem e seu cognitivo, desenvolvendo assim um ensino e aprendizado. Em uma simples brincadeira na sala de aula as crianças podem compreender os principais valores, como respeitar a vez do colega na brincadeira, usar sua criatividade e imaginação e conviver com outras pessoas. Segundo França (2016), "É no brincar, muito provavelmente só no brincar, que tanto a criança quanto o adulto podem experimentar um sentimento de liberdade para cria-se”. É neste momento de liberdade de sentimentos que é realizado o processo de desenvolvimento da criança, criando se os vínculos afetivos para sua formação.

Os gestos de afeto devem ser realizados de uma forma natural e contínua, na qual através deles sejam realizadas trocas de conhecimentos entre ambas as partes, um deve compreender o outro. É 
necessário que os professores estabeleçam os vínculos afetivos com a criança, sempre respeitando-a, ouvindo o que ela tem a falar, dando vez e voz para ela poder expressar-se. A relação professor-aluno fica mais importante na etapa da Educação Infantil, devido à criança estar passando por adaptação, nessa fase tudo que acontece com a criança é novo para ela. Ela sentirá medo e insegurança, por isso, a importância da relação professor-aluno torna-se mais importante nesta etapa.

O desenvolvimento da criança dependerá de profissionais qualificados, que estejam capacitados para ensinar e aprender junto às crianças. A educação Infantil é uma etapa muito importante na vida da criança, pois possibilitará viver em conjunto com diversas pessoas, de diversos mundo, com diversas culturas, e esse choque cultural será importante para o desenvolvimento dela. (CARDOSO, 2015, p. 16)

Nessa etapa o professor deve procurar conhecer a realidade de seus alunos, procurando sempre novas maneiras de promover um ensino e aprendizado de acordo com as necessidades das crianças. Ele irá construir, através da afetividade, novos métodos que irão contribuir na formação da criança, deixando-a segura de seus sentimentos e de suas atitudes, na qual ela poderá compreender o que está acontecendo ao seu redor, dando desta forma mais possibilidades dela se desenvolver em todos os aspectos, ocorrendo assim um ensino e aprendizado de qualidade.

O professor deve estar sempre preparado para o novo e deve ter em mente que no ambiente escolar ele é apenas o mediador. Ser educador vai além de transmitir conhecimento, pois a todo instante o educador está aprendendo com o educando, através da mais bela forma, sendo através do afeto, do respeito e até mesmo através de um sorriso, pois as crianças sempre têm algo para ensinar, o educador deve estar sempre à disposição das crianças para juntos construírem novos conhecimentos. Para Schaefer (2015, p. 145) "mais significativo do que o professor dar um beijo ou um abraço no aluno, é o melhor presente, o respeito e a demonstração de interesse pela vida do aluno".

Pois o conhecimento e a educação não são algo que podem ser construídos sozinhos, mas em conjunto, nos quais são construídos diariamente através da troca de afetos que vai além de beijos e abraços, mas que é construída através de um olhar sincero, de uma conversa, saber ouvir a criança, pois o educar e o cuidar são indissociáveis, os dois andam juntos. Não existe educação sem cuidado, os dois são muito importantes para a formação e aprendizado da criança. Conforme Schaefer (2015, p.15o), "aprendizagem e afetividade constituem um par inseparável quando inseridos no processo de ensino e aprendizado".

Através do afeto a criança pode desenvolver o cognitivo, a leitura e escrita, passando assim a construir um vocabulário de qualidade, pois não é possível construir uma aprendizagem sem o afeto, 
visto que é o afeto que move todas as ações do indivíduo. As pessoas são movidas por sentimentos, se o psicológico está bem, suas possibilidades de se desenvolverem da maneira correta no decorrer de cada fase do desenvolvimento infantil será maior.

Portanto, faz-se necessário que, o professor esteja sempre estimulando seu aluno, ocorrendo trocas de conhecimentos entre os dois. O educador deve tratar a criança com amor e respeito, deixando-a livre para expor suas opiniões e juntos construírem um novo aprendizado, no qual irá contribuir na formação do professor e na formação do aluno. Deve haver ainda, empatia entre ambas as partes, para que assim possa ser realizado um ensino de qualidade baseando sempre no afeto.

\section{METODOLOGIA}

Essa pesquisa teve como embasamento teórico artigos bibliográficos que requerem um estudo mais aprofundado sobre o assunto. Assunto esse que buscará através de textos identificar a importância da afetividade na educação infantil para o processo de ensino e aprendizado. Conforme Marconi Lakatos (2019): “a pesquisa bibliográfica não é mera repetição do que já foi dito ou escrito sobre certo assunto, visto que propicia o exame de um tema sob novo enfoque ou abordagem, chegando à conclusão inovadora".

Assim como cita Marconi Lakatos (2019), através da pesquisa bibliográfica é possível serem realizadas várias opiniões sobre determinado assunto, sempre adquirindo novos conhecimentos e resultados acerca do problema abordado, podendo assim ser compreendido de várias maneiras.

As orientações abaixo foram seguidas e com isso dispôs-se a definir os critérios das publicações analisadas, que foram estes:

a) deveriam ser elas encontradas na plataforma de busca Portal de periódicos da CAPES²;

b) deveriam ser elas encontradas com as palavras-chave: Afetividade AND Educação Infantil. Estas foram pedidas no título das publicações;

c) deveriam ser elas artigos publicados nos últimos 5 anos;

Definidos tais critérios, encontramos 2 produções. Assim, obteve-se a quantidade de 2 artigos a serem relidos e analisados, estes estão apresentados no Quadro I.

\footnotetext{
Quadro I- Produções Analisadas.
}

\footnotetext{
2 Plataforma Portal de Periódicos da CAPES disponível no endereço: https://www-periodicos-capes-govbr.ez24.periodicos.capes.gov.br/index.php?. Acesso em is de agosto de 2020.
} 


\begin{tabular}{|c|l|}
\hline Qtde & \multicolumn{1}{|c|}{ Produções Analisadas } \\
\hline I & $\begin{array}{l}\text { Leandra Tonsach Alexandre. A importância da afetividade nas relações pedagógicas da } \\
\text { educação infantil. Revista Even. Pedagóg. Número Regular: Formação de Professores e } \\
\text { Desafios da Escola no Século XX1, Sinop, v,7, n, 2 ( I9.ed.), p. 486-497, jun. / jul. 2or6. }\end{array}$ \\
\hline 2 & $\begin{array}{l}\text { Gabriela de Castro Loech Amorim, Ana Maria Gimenes Corrêia Calil.A afetividade nos } \\
\text { documentos oficiais da educação infantil: uma questão a ser explorada. Revista Devir } \\
\text { Educação, Lavras. Vol. 4, n.I, p.93-IIjjan/jun. 2020. }\end{array}$ \\
\hline
\end{tabular}

Fonte: A pesquisadora. (2020)

Constatou-se que, embora o limite temporal seja entre os anos 2015 a 2020, não foram encontradas publicações nos anos 2015, 2017, 2018 e 2019. Após a coleta das produções, foram realizadas leituras de todas elas, nos quais as principais informações foram compiladas. Posteriormente, foi realizada uma análise descritiva delas, buscando estabelecer uma compreensão geral do que é proposto no artigo.

Para fins de análise das produções, utilizou-se como técnica, a Análise Textual Discursiva (ATD), tendo como base o estudo de Moraes e Galiazzi (2016), os quais a define como "um processo auto-organizado de construção de novos significados em relação a determinados fenômenos estudados, a partir de materiais textuais referentes a esses fenômenos" (MORAES; GALIAZZI, 20I6, p. 67).

A "auto-organização" referida pelos autores dá-se por meio de processos de leituras dos materiais que compõem os textos do corpus da pesquisa, são estes processos: "a desconstrução dos textos do 'corpus', a unitariação; o estabelecimento de relação entre os elementos unitários, a categorização; o captar o novo emergente em que a nova compreensão é comunicada e validada" (MORAES; GALIAZZI, 2016, p. 34).

Nesse sentido, foram encaminhadas as análises das 2 produções percorrendo a proposta de ATD de Moraes e Galiazzi (2016), a partir da qual elencou-se quadros das informações referentes à Afetividade na relação professor-aluno na Educação Infantil. Estas serão apresentadas no tópico análise e discussões.

\section{ANÁLISE E DISCUSSÕES}

Os tópicos a seguir discorrem sobre a análise e discussões dessa pesquisa. Tendo em vista os objetivos almejados com este estudo, optou-se por apresentar tópicos específicos em que, no primeiro trata-se das concepções de afetividade na educação infantil, o segundo, apresentam-se os sentidos da afetividade na relação professor-aluno e o terceiro vem identificando a importância da afetividade nas práticas pedagógicas para o processo de ensino e aprendizado na educação infantil. 


\section{3.r Concepções de Afetividade na Educação Infantil}

Logo após as buscas das produções, foram realizadas leituras, na qual deveriam ser identificados se tratava-se de cunho empírico ou teórico, foram realizadas convergências sobre as linhas de pensamentos dos autores citados no referencial teórico e nas produções encontradas no portal de periódicos da CAPES, com o intuito de compreender o que versa as concepções de afetividade na educação infantil.

No quadro 2: Será exposto a definição das produções encontradas ao longo do processo, identificando a concepção da afetividade na Educação Infantil, encontradas em cada um deles.

Quadro 2- Concepções de Afetividade na Educação Infantil

\begin{tabular}{|c|l|l|}
\hline Autor & $\begin{array}{c}\text { Tipo de } \\
\text { texto }\end{array}$ & \multicolumn{1}{|c|}{ Concepções de Afetividade na Educação Infantil } \\
\hline $\begin{array}{c}\text { ALEXANDRE } \\
(2016)\end{array}$ & Empírico & $\begin{array}{l}\text { Segundo Galvão (1995) As emoções assim como os sentimentos e os } \\
\text { desejos, são manifestações da vida afetiva. Na linguagem comum } \\
\text { costuma-se substituir emoção por afetividade, tratando os termos como } \\
\text { sinônimos. Todavia, não o são. A afetividade é um conceito mais } \\
\text { abrangente no qual se inserem várias manifestações. (p. 489). }\end{array}$ \\
\hline $\begin{array}{c}\text { AMORIM, } \\
\text { CALIL (2020) }\end{array}$ & Teórico & $\begin{array}{l}\text { Mahoney, Almeida (20Io), esclarece que afetividade é um conceito } \\
\text { amplo, 'que além de envolver um componente orgânico, corporal, motor } \\
\text { é plástico que é a emoção, apresenta também um componente cognitivo". } \\
\text { (p, Io8). }\end{array}$ \\
\hline
\end{tabular}

Fonte: A pesquisadora

Nas produções de Alexandre (2016), e de Amorim, Calil (2020), foram encontradas concepções de afetividade que vão ao encontro das discussões de Giovanetti (2017). Pois a afetividade é o que dá sentido à vida. Assim como cita Galvão (1995), citado na produção de Alexandre (2016), a afetividade é o território das emoções, no qual será desenvolvido através dela, os desejos os pensamentos e as ações, a afetividade estar interligada a várias manifestações da vida do ser humano, desde a fala aos gestos e ações. Os sentimentos são o que dá sentido à vida das crianças, os laços afetivos são responsáveis pelo o pleno desenvolvimento e aprendizado.

Conforme Mahoney, Almeida (2010, apud Amorim, Calil 2020), são as ações desenvolvidas através do afeto que são responsáveis pela construção de novos conhecimentos, que estimulam o cognitivo, além de promover na criança equilíbrio emocional e motor, vindo a facilitar o conviver social com outras pessoas. Quando o afeto é desenvolvido da maneira correta ocorrerá uma aprendizagem de qualidade, na qual as crianças irão se desenvolver de forma integral. 
Para Santos (2016), a afetividade é algo essencial para o processo de ensino e aprendizagem na Educação Infantil, na qual através do afeto as crianças poderão aprender a conviver com outras pessoas, conhecendo coisas novas e aprenderá a viver em sociedade. Os vínculos afetivos desenvolvidos nesta etapa serão de grande relevância para o aprendizado delas. Silva (2017), relata que, as crianças que tem dificuldades na aprendizagem também não possuem uma linguagem e escrita adequada, além de comprometer seu relacionamento com outras pessoas.

Os pensamentos dos autores Santos (2016), e Silva (2017), convergem com os mesmos pensamentos de Alexandre (2016), e de Amorim, Calil (2020). Pois ambos compreendem que a afetividade tem uma função essencial no processo de formação das crianças, e no processo de ensino e aprendizado. Os laços afetivos são de grande relevância, nesta fase, pois através dele as crianças poderão aprender de uma forma integral, devido à afetividade ser um sentimento que afeta toda a estrutura do ser humano, sendo considerada como um território de manifestações, é necessário que o afeto esteja presente em todos os momentos da vida da criança, principalmente na Educação Infantil, devido ser a etapa na qual a criança requer mais atenção e afeto.

Piaget (1973 apud Cunha, Amancio, Baccelli, 2020) ressalta que a ausência do afeto prejudica o desenvolvimento da criança, além de afetar a inteligência e o interesse por determinados assuntos, que são essenciais para seu desenvolvimento. Portanto, as trocas de afeto desenvolvidas na Educação Infantil tornam-se essenciais nesta fase da vida da criança. Pois é através do afeto que irão ser desenvolvidos a autonomia, o cognitivo, a imaginação, a criatividade, a linguagem e escrita e o raciocínio lógico, além de facilitar a convivência das crianças com outras pessoas. Através do afeto desenvolvido no ambiente escolar as crianças terão mais possibilidades de se desenvolver de uma maneira integral, e o mais importante, vão aprender a dominar suas emoções como, raiva medo, insegurança, além de aprender a viver em sociedade, aprendendo os principais valores como o respeito, e a honestidade, e a serem cidadãos do bem.

\subsection{Os Sentidos da Afetividade na relação Professor-Aluno}

Foram realizados procedimentos de leituras nas produções, com o intuito de identificar, os sentidos de afetividade na relação professor-aluno, na qual vem se se destacando no quadro 3 . 


\section{Quadro 3: Os sentidos da Afetividade na relação Professor-Aluno}

\begin{tabular}{|c|l|}
\hline Autor & \multicolumn{1}{|c|}{ Os Sentidos da Afetividade na Relação Professor-Aluno } \\
\hline $\begin{array}{c}\text { ALEXANDRE } \\
(2016)\end{array}$ & $\begin{array}{c}\text { A relação entre o professor e aluno, deve ser de amor, pois na educação infantil é a } \\
\text { primeira etapa de sua vida depois da família, onde a aprendizagem dar-se de forma } \\
\text { integral. (p. 494). }\end{array}$ \\
\hline $\begin{array}{c}\text { AMORIM, CALIL } \\
(2020)\end{array}$ & $\begin{array}{l}\text { cabe ao professor conduzir o aluno a momentos que propiciem a este ser afetado de } \\
\text { forma positiva, assegurando situações que trabalhem o conhecimento de si, do } \\
\text { outro e de sua autoestima. (p. Io8). }\end{array}$ \\
\hline
\end{tabular}

Fonte: A pesquisadora.

Nas produções de Alexandre (2016) e de Amorim, Calil (2020) foram encontradas concepções de afetividade que vão ao encontro das discussões de Cardoso (2015), na qual ressalta que a relação entre o professor-aluno deve ser de amor e de confiança, os educadores precisam desenvolver nos educandos, a autoestima através de estímulos como conversas, brincadeiras, jogos, que permitam que a criança conheça a si e ao outro sempre com respeito e afeto.

A BNCC (2017), ressalta que essas ações podem ser realizadas através dos campos de experiências, que permitem que as crianças conheçam a si mesmo e ao outro, formando assim os laços afetivos, Amorim Calil (2020) ressalta que as relações afetivas estabelecidas entre o professor-aluno são de fundamental importância para este processo de conhecimento, na qual o aluno vai desenvolver sua autonomia, sua autoestima e seu aprendizado. Para Alexandre (2016) a relação entre o professor-aluno deve ser de amor, deve haver respeito e empatia entre ambas as partes.

Segundo Piaget (1962 apud Cunha, Amancio, Baccelli, 2020) a afetividade é essencial para o processo de desenvolvimento da inteligência, pois sem as trocas de afeto não haveria aprendizado, e os indivíduos não se sentiriam motivados para buscar novos conhecimentos. O afeto é de grande relevância para o pleno desenvolvimento do indivíduo, pois é através dele que será desenvolvida sua habilidade e sua inteligência. Portanto, as trocas de afeto no ambiente escolar devem ocorrer diariamente. Pois é no ambiente escolar que a criança vai ter o primeiro contato com a sociedade. A escola é a segunda responsável pelo desenvolvimento da criança depois da família, por isso os professores devem promover momentos na qual a criança possa se desenvolver da melhor forma e em todos os aspectos.

Schaefer (2015), afirma que o respeito e a preocupação com a vida do aluno têm um significado muito importante para o desenvolvimento da criança. Pois as trocas de afeto realizadas na Educação Infantil vão muito além de contatos físicos como beijos e abraços, pois estas práticas afetivas têm uma 
função muito maior, na vida das crianças e nas atividades curriculares e na relação entre o professor e o aluno, pois o afeto é realizado através do diálogo do cuidado e do respeito.

(FREIRE 1999, p. 49) ressalta que: a importância dos laços afetivos, no ambiente escolar deve ser algo que deve ser refletido diariamente. O professor deve estar sempre estimulando seus alunos e sempre estar afetando-lhes de uma forma positiva, sempre com cuidado e respeito, pois é através do afeto que as crianças vão aprender coisas novas, no qual irá conhecer a si e ao outro, aprendendo a viver em sociedade

com diversas pessoas e culturas. É no ambiente escolar que elas vão formar sua personalidade, é neste processo de reconhecimento que será desenvolvido o aprendizado, vindo desta maneira conhecer a realidade e cultura de seus colegas formando assim uma aprendizagem.

Para Wallon (1981 apud Amorim, Calil 2020), as crianças se formam através da cultura e é através destas culturas que serão desenvolvidos os aprendizados e as interações com o meio, e esta cultura devem se trabalhada no ambiente escolar para que as crianças aprendam a se colocar no lugar do outro, é através destas trocas de afeto que as crianças vão compreender o que é certo ou errado, e irão aprender a respeitar seus colegas e suas culturas, o professor deve estar sempre estimulando seu aluno, para que ocorra aprendizado e deve buscar afetar os alunos de uma forma positiva, independente da classe social ou religiosa.

Para Cardoso (2015), estes aprendizados realizados através da cultura são de grande relevância para a vida e aprendizagem das crianças, pois elas irão compreender que as pessoas são diferentes, mais que todas merecem respeito e que todas têm direitos. Para Alexandre (2016), e Amorim, Calil (2020), o professor deve estabelecer uma relação de amor com a criança afetando as mesmas de uma forma positiva, para que possa vir a desenvolver sua autonomia e autoestima, além de aprimorar seus conhecimentos, e aprender a conviver com outras pessoas independente de suas culturas, podendo assim ser formando um ensino de qualidade de acordo com as necessidades de cada criança.

\subsection{A Importância da Afetividade nas Práticas Pedagógicas para o processo de Ensino e Aprendizado na Educação Infantil}

Este estudo tem como intuito compreender a importância da afetividade nas práticas pedagógicas para o processo de ensino e aprendizado na Educação Infantil, identificando a partir das produções analisadas os principais métodos utilizados nas práticas pedagógicas curriculares, na qual eles vêm sendo destacados no quadro 4 . 
Quadro 4-A importância da afetividade nas práticas pedagógicas para o Processo de Ensino e Aprendizado na Educação Infantil.

\begin{tabular}{|c|l|}
\hline Autor & $\begin{array}{l}\text { A Importância da Afetividade nas práticas Pedagógicas para o Processo } \\
\text { de Ensino e Aprendizado na Educação Infantil }\end{array}$ \\
\hline $\begin{array}{c}\text { ALEXANDRE } \\
\text { (2016) }\end{array}$ & $\begin{array}{l}\text { O trabalho pedagógico não pode dissociar - se da afetividade que } \\
\text { compõe as relações humanas e os sentidos produzidos sobre o mundo e } \\
\text { a vida, facilitando o processo de aprendizagem. (p. 495). }\end{array}$ \\
\hline $\begin{array}{c}\text { AMORIM, } \\
\text { CALIL (2020) }\end{array}$ & $\begin{array}{l}\text { A prática educativa necessita ser pensada para que as atividades possam } \\
\text { despertar nas crianças seu sentido de autonomia e possa m também } \\
\text { explorar seus objetos através de suas características e funções. (p.Ioo) }\end{array}$ \\
\hline
\end{tabular}

Fonte: A pesquisadora.

Nas produções de Alexandre (2016) e de Amorim, Calil (2020) foram encontradas concepções de afetividade que vão ao encontro das discussões da BNCC (2017), no qual sugere que as crianças da etapa da Educação Infantil tenham direitos a práticas pedagógicas, e que sejam desenvolvidos métodos que venha a contribuir com a aprendizagem das mesmas de uma formar mais eficaz, desenvolvendo nas mesmas a autonomia, na qual elas poderão explorar novos conhecimentos que será de grande relevância para seu processo de aprendizagem.

A BNCC (2017) converge com o pensamento dos autores Alexandre (2016) e de Amorim, Calil (2020). Pois as práticas pedagógicas devem ter um sentido. Sabendo-se que as crianças são seres que aprendem através das brincadeiras, das interações e com o meio, cabe aos professores desenvolverem atividades pedagógicas que desenvolvam o aprendizado dos alunos, na qual seja realizados os cincos campos de experiências da (BNCC), para que assim as crianças possam desenvolver novas habilidades. A afetividade tem uma grande função no processo de ensino e aprendizado, pois através dela os alunos terão mais possibilidades de compreender as atividades curriculares. Portanto, o afeto é fundamental no processo de ensino e nas práticas pedagógica, desenvolvidas no ambiente escolar.

Estas atividades podem ser realizadas através de brincadeiras nas quais estarão desenvolvendo o emocional, o social, o cognitivo, a imaginação e criatividade das crianças, as atividades devem ter sempre um foco e devem ser sempre acompanhadas de afeto. Para França (2016), é no momento das brincadeiras que o indivíduo cria-se. É neste momento que a criança adquirir novos aprendizados e novas habilidades, a brincadeira é uma prática bastante importante na etapa da Educação Infantil.

Pois ela tem uma grande contribuição nos laços afetivos, além de ser um método bastante eficaz no processo de desenvolvimento da criança, o brincar na (BNCC) é um dos direitos mais essenciais na 
Educação Infantil, pois é através do brincar que as crianças vão adquirir uma aprendizagem, na qual poderão se desenvolver de uma forma integral, aprendendo seus princípios e valores.

Para Alexandre (2016) as práticas pedagógicas devem sempre estar em sintonia com a afetividade, sempre buscando promover a autonomia e o aprendizado das crianças de uma forma na qual seja desenvolvido o cognitivo, a imaginação, os laços afetivos devem ser realizados constantemente. De acordo com a Lei (1996) Lei de Diretrizes e Bases da Educação Nacional (LDB), a Educação Infantil é o local no qual a criança vai aprender diversas coisas, no qual ela irá se desenvolver de uma forma integral.

As crianças possuem uma grande facilidade de aprender as coisas ao seu redor. Portanto, as práticas pedagógicas devem sempre ser realizadas com um propósito, no qual venha a desenvolver o aprendizado das crianças de uma forma integral, seja através de rodas de conversas, de brincadeiras, jogos e até mesmo pinturas, são estas atividades curriculares que vão desenvolver nas crianças um aprendizado de qualidade, que além de fortalecer os vínculos afetivos, vai ser de grande relevância para o desenvolvimento delas.

\section{${ }_{4}$ CONSIDERAÇÕES FINAIS}

Ao buscar investigar sobre a importância da afetividade na educação infantil para o processo de ensino e aprendizado, verificou-se a importância dos laços afetivos como peça fundamental para o

processo de formação das crianças. Sabe-se que essas aprendem de acordo com o meio no qual estão inseridas. Através desse estudo, foi possível identificar como os periódicos apresentam a afetividade na relação professor-aluno no processo de ensino e aprendizagem na educação infantil. Baseado nisso, averiguou-se os seguintes objetivos específicos: compreender os sentidos de afetividade apresentados nos periódicos; identificar os discursos sobre afetividade na relação-professor-aluno na Educação Infantil; averiguar a importâncias dos laços afetivos nas práticas pedagógicas apresentados nos periódicos.

Ao caminhar sobre a temática, identificou-se os sentidos de afetividade nos artigos encontrados no portal de periódicos da CAPES, nos quais deveriam ser publicados nos últimos cincos anos. Foram realizadas as buscas, onde foram encontradas duas produções, nas quais foram identificadas as seguintes palavras-chave: afetividade e educação infantil, essas produções vêm contribuído na análise e discussão desta pesquisa. No primeiro foram identificando a concepção de afetividade, o segundo vem abordar sobre a relação entre o professor-aluno, já o terceiro vem destacando a importância das práticas pedagógicas no ambiente escolar, pelos quais foram realizadas leituras mais aprofundadas com o intuito de investigar em cada um deles a importância da afetividade para o processo de ensino e aprendizado das 
crianças da etapa da Educação infantil. Identificando assim, como os laços afetivos entre o professoraluno podem influenciar no processo de desenvolvimento e aprendizado das crianças.

A partir dos estudos realizados nas produções encontradas, verificou-se que, a afetividade no ambiente escolar deve ocorrer de uma forma natural e contínua, na qual a criança possa sentir-se confiante e que venha a desenvolver seu psicológico, aprendendo a dominar suas emoções e fraquezas, além de conviver socialmente com outras crianças. Assim, adquirindo novos conhecimentos que irão facilitar sua vida futuramente. Nesse estudo foram utilizados pensamentos de autores como Wallon, França, Schaefer, Silva. O estudo teve como embasamento documentos como, Estatuto da Criança e do Adolescente (ECA), a Lei de Diretrizes e Bases da Educação Nacional (LDB), e a Base Nacional Comum Curricular (BNCC), que vêm trazendo alguns direitos das crianças, para que seja possível estabelecer os vínculos afetivos de uma forma lúdica, que possa proporcionar nas crianças um ensino e aprendizado de qualidade e de acordo com as necessidades de cada criança.

Averiguou-se, a partir dessa pesquisa a importância dos laços afetivos entre o professor-aluno no ambiente escolar como método essencial para o processo de ensino e aprendizado das crianças da etapa da educação infantil. Sabendo-se que o ambiente escolar é um local de aprendizado, no qual as crianças poderão aprimorar seus conhecimentos e adquirir novas habilidades que irão contribuir na sua formação e personalidade. Cabe ao professor, proporcionar momentos nos quais as crianças possam se desenvolver da melhor forma, seja através de práticas pedagógicas, que além de promover nas crianças uma aprendizagem em relação ao conteúdo também proporcionarão a elas os valores.

Os laços afetivos nesta fase tornam-se essenciais, pois quando a criança está em um lugar tranquilo, em que possa expor suas opiniões e quando estimulada, terá mais possibilidades de aprendizagem. A escola tem uma grande influência nessa etapa de desenvolvimento da criança, pois é no ambiente escolar que elas irão ter a oportunidade de interagir com outras crianças, podendo conhecer coisas novas, contribuindo desta forma com a formação mútua, formando assim, um ensino e aprendizagem de qualidade, pois o afeto se torna essencial para o processo de desenvolvimento integral da criança, que está em constante mudança.

\section{REFERÊNCIAS BIBLIOGRÁFICAS}

BRASIL. Lei n ${ }^{\circ}$ 9.394, Lei de Diretrizes e Bases da Educação Nacional, de 20 de dezembro de 1996. Disponível em: http://www.planalto.gov.br/ccivil_03/leis/9394.htm. Acesso em 27 de agosto de 2020

BRASIL, Lei n ${ }^{\circ} 8.069$, Estatuto da Criança e do Adolescente, Lei n ${ }^{\circ} .069$, 13 de julho de 199o. Disponível em: http://planalto.gov.br/ccivil_o3leis/ı8069.htm. Acesso em 27 de agosto de 2020. 
BRASIL. Resolução CNE/CP $\mathrm{N}^{\circ}$ 2, de 22 de dezembro de 2017. Institui e orienta a implantação da Base Nacional Comum Curricular, a ser respeitada obrigatoriamente ao longo das etapas e respectivas modalidades no âmbito da Educação Básica. Brasília. DF: CNE, 2017.

CARDOSO. M.G. A Importância da Afetividade na Educação Infantil, 2015. P.12-16.Disponível em: http://dspace.bc.uepb.edu.br/jspui/bitstream/123456789/10463/1/pdf. Acesso em 20 de agosto de 2020.

França, Sirlene Carvalho Rocha, Educação lúdica: perspectiva para uma aprendizagem mais agradável. Irecê: itacaiúnas, 2016.

FREIRE, Paulo. Pedagogia da autonomia. Saberes Necessários à Práticas Educativas. São Paulo: Paz e Terra, 1999. Disponível em: http://www.pensamentobiocentrico.com.br/content/edo6_arto3.php. Acesso em i7 de dezembro de 2020 .

Gabriela de Castro Loech Amorim, Ana Maria Gimenes Corrêia Calil.A afetividade nos documentos oficiais da educação infantil: uma questão a ser explorada. Revista Devir Educação, Lavras. Vol. 4, n.I, p.93-II5 jan /jun. 2020. Disponível em: https://www-periodicos-capes-govbr.ez24.periodicos.capes.gov.br/index.php?. Acesso em is de agosto de 2020.

GALVÃO, Izabel, Henri Wallon: uma concepção dialética do desenvolvimento infantil/Izabel Galvão. Petrópolis: Vozes, 1995.

Giovanetti, José Paulo. Psicoterapia fenomenológico - existencial: fundamentos filosóficos antropológicos. Via veria, 2017.

LAKATOS, Eva Maria e Marconi Marina de Andrade, técnica de pesquisa: planejamento e execução de pesquisa, amostragem e técnicas de pesquisa, elaboração, análise e interpretação de dados. 3, ed. São Paulo: Atlas, 1996.

Leandra Tonsach Alexandre. A importância da afetividade nas relaç̃̃es pedagógicas da educação infantil. Revista Even. Pedagóg. Número Regular: Formação de Professores e Desafios da Escola no Século XX1, Sinop, v,7, n, 2 ( 19.ed.), p. 486-497, jun. / jul. 2016. Disponível em: https://www-periodicos-capes-govbr.ez24.periodicos.capes.gov.br/index.php?. Acesso em is de agosto de 2020.

MAHONEY, Abigail Alvarenga; ALMEIDA, Laurinda Ramalho. A constituição da pessoa na proposta de Henri Wallon. São Paulo: Loyola,2004.

MORAES, Roque; GALIAZZI, Maria do Carmo. Análise Textual Discursiva. 3 ed. rev. ampl. Ijuí: Unijuí, 2016.

PIAGET, Jean. La relación del afecto com inteligência em el desarrollo mental del miño. Universidade Autónoma Metropolitana; Xochimilco. 1962. Disponível em: Revista, Doxa: Rev. Bras. Psico. e Educ. https://www-periodicos-capes-gov-br.ez24.periodicos.capes.gov.br/index.php? Acesso em i7 de dezembro de 2020 .

PIAGET, Jean. O tempo e o desenvolvimento intelectual da criança. Rio de Janeiro: Forense, 1973. Disponível em: Revista, Doxa: Ver. Bras. Psico. e Educ. https://www-periodicos-capes-govbr.ez24.periodicos.capes.gov.br/index.php? Acesso em 17 de dezembro de 2020. 
SANTOS. C.S. O espaço social das aldeias SOS em Santa Maria: possibilidades e desafio para a atuação do pedagogo. 2016

SCHAEFER, Jéssica Simone Galdino. Afetividade entre professor e aluno no processo de ensino aprendizagem. Revista Eventos Pedagógicos, 15. Ed. Jun/jul. 2015, p. 142-151. Disponível em: file:///C:/User/Diana/Dowloads/r834-5724-IPB\%20(I).pdf. Acesso em 20 de agosto de 2020.

SILVA, Marcelo, Carlos da. Dificuldade de aprendizagem do histórico ao diagnóstico. Disponível em: http://www.psicológia.com.pt. Acesso em 20 de agosto de 2020.

WALLON, HENRI. A evolução psicológica da criança. Lisboa: Edições 70, 1981/1995. Disponível em: Revista Even. Pedagóg. https://www-periodicos-capes-gov-br.ez24.periodicos.capes.gov.br/index.php?. Acesso em 20 de agosto de 2020.

WALLON, Henry. Do ato ao pensamento. França, 1942. Disponível em: Revista, Doxa: Ver. Bras. Psico. E Educ. https://www-periodicos-capes-gov-br.ez24.periodicos.capes.gov.br/index.php? Acesso em i7 de dezembro de 2020 . 